\title{
Survey of attitude and knowledge of reproductive health among middle school students in Luoyang, China
}

\author{
P. Wang ${ }^{1}$, Y.J. Zhang ${ }^{2}$, X.J. Pan ${ }^{1}$, X.Y. Xia ${ }^{1}$ and S.Y. Lv ${ }^{1}$ \\ ${ }^{1}$ Department of Preventive Medicine, \\ Henan Science and Technology University, Luoyang, China \\ ${ }^{2}$ Department of Gastroenterology, \\ First Affiliated Hospital, Henan University of Science and Technology, \\ Luoyang, China
}

Corresponding author: Y.J. Zhang

E-mail: yingjianzhangcn@163.com

Genet. Mol. Res. 13 (3): 6168-6176 (2014)

Received May 16, 2013

Accepted October 3, 2013

Published March 24, 2014

DOI http://dx.doi.org/10.4238/2014.March.24.17

\begin{abstract}
The aim of this study was to assess the knowledge and attitude of AIDS and sexual behavior of middle school students. Structural questionnaires were designed to interview 1980 junior and senior middle school students about their basic knowledge, attitude, and behavior with respect to AIDS and sexual behavior. Students were recruited from the six most common middle schools of the six regions in Luoyang City of the Henan Province of China by cluster sampling from September to December of 2004. Results showed that $54.5 \%$ of students had not learned about the prevention of HIV/AIDS in school, and $38.3 \%$ of students did not have any knowledge about the route of transmission of HIV/AIDS. Furthermore, $91.2 \%$ of students were reluctant to share a classroom with HIV/AIDS patients. Approximately $21.7 \%$ of students had read books, watched videos, and consulted other media related to sex, $1.1 \%$ of students had had sexual intercourse during high school, and $80.5 \%$ believed that health education on HIV/
\end{abstract}




\begin{abstract}
AIDS and sex was necessary. The results of this survey showed that middle school students have little knowledge about HIV/AIDS and sex. Therefore, health education programs for HIV/AIDS prevention and sexual health should be developed as soon as possible to help students peacefully get through a sexually puzzling period of life.
\end{abstract}

Key words: Middle school students; AIDS; Sexual behavior; Knowledge and attitude

\title{
INTRODUCTION
}

Health education professionals have different views on what should be considered the proper goals of school-based sex education programs and which outcomes are best evaluated. Several reviews on the evidence of these issues have nonetheless indicated that no currently existing program will effectively prevent the majority of youth from having sex during their school years (Lauszus et al., 2012). Sexual and reproductive health among adolescents has become an increasingly important issue and has aroused international concern. One survey showed that most college students lacked knowledge about reproductive health, and only $17.9 \%$ of the respondents knew the appropriate time of abortion. Survey data also showed that most respondents had a high-risk attitude about sex; $58.7 \%$ would accept premarital sex, and $29.7 \%$ had a negative attitude toward contraception. Moreover, $18.5 \%$ of the respondents were sexually active (Zhou et al., 2012). Based on estimations of the United Nations AIDS program and the World Health Organization (WHO), there are 1600 new patients diagnosed with AIDS every day, of which young people comprise over half (Wu et al., 2011). China has the largest number of young people in the world (Hong et al., 2011a). A Chinese population investigation in 2000 reported that there were 32,300,000 adolescents ranging in age from 10 to 20 years, which accounted for about $26 \%$ of the total national population (Liao et al., 2012).

Chinese adolescents have a tendency toward precocious sexual attitudes and show variations in sexual morality, and the average age of first sexual intercourse is decreasing. In addition, considering their poor knowledge and dangerous attitudes of reproductive health, the incidence of AIDS is expanding from the high-risk population to the general population (Zhu et al., 2012). Young people are facing an increasingly potent risk of acquiring AIDS; $7.4 \%$ of AIDS patients are adolescents below the age of 19 , who were the focus as a special group under treatment of AIDS (Khan et al., 2011). In order to develop better health education programs, better understanding of the knowledge and attitude of AIDS and sexual behavior among middle school students is needed. Therefore, we investigated such knowledge and attitudes among middle school students in China to provide guidelines for health education on AIDS and sexual behavior.

\section{MATERIAL AND METHODS}

\section{Sample population}

The basic knowledge, attitude, and behavior of AIDS and sexual behavior were evaluated among 1980 junior and senior middle school students of the six most common middle 
schools of the six regions in Luoyang City of the Henan Province of China from September to December of 2011. A stratified structural questionnaire was used. Every structure included a junior region and a senior region, and the class was used as the sampling unit. In all, 1980 students were interviewed with a 1.04:1 male:female ratio; 1946 questionnaires were successfully completed, comprising $98.28 \%$ of the interviewees (Table 1 ).

\begin{tabular}{lccc}
\multicolumn{2}{l}{ Table 1. Composition of interview. } & & \\
\hline & Male & Female & Total \\
\hline Grade & & & 966 \\
$\quad$ Junior grade & 491 & 475 & 980 \\
$\quad$ Senior grade & 501 & 479 & 1493 \\
Region & & 768 & 453 \\
Central city & 725 & 186 & 1946 \\
$\quad$ Non-central city* & 267 & 954 & \\
Total & 992 &
\end{tabular}

*Non-central city = peripheral city, countryside combined with city.

\section{Methods}

Structural questionnaires were introduced. The "questionnaire of attitude and behavior about AIDS in middle school students" was designed at the basis of institution of nation and Luoyang city of Henan Province in China, and included the following factors: demographics, physiological knowledge of adolescence and growth, knowledge of AIDS and sexual diseases, attitude about sex during youth, and the need for reproductive health and sexual behavior education during the period of adolescence (Jain et al., 2011). This investigation was performed by investigators and trained researchers with the assistance of education organizations, and students completed the questionnaires anonymously as a class unit. Questionnaire were distributed and gathered together, and each student completed it individually.

The SAS 8.1 statistical software was used to analyze the data. Count data were compared by using the chi-squared test or the Fisher exact probability test.

\section{RESULTS}

\section{Need for knowledge of AIDS and sexual diseases}

\section{Necessity of education about AIDS and health}

Most students (over 80\%) agreed with the statement "education of AIDS and sexual health is very necessary", among which female junior school students showed the highest proportion of $87.7 \%$. There were no differences between various districts $\left(\chi^{2}=0.2360, \mathrm{P}\right.$ $>0.05)$, but there was a significant difference between male and female students among various districts $\left(\chi^{2}=32.1427, \mathrm{P}<0.05\right)$. Students from non-central cities showed a higher proportion of agreement $(84.5 \%)$ than did those from central cities $(77.1 \%)\left(\chi^{2}=14.3851\right.$, $\mathrm{P}<0.05)$, and female students also showed a higher proportion of agreement $(85.4 \%)$ than male students $(75.8 \%)\left(\chi^{2}=28.7026, \mathrm{P}<0.05\right)($ Table 2$)$. 
Table 2. Need for knowledge of AIDS and sexual disease (N, \%).

\begin{tabular}{|c|c|c|c|c|c|c|}
\hline & \multicolumn{3}{|c|}{$\begin{array}{l}\text { Great necessity of education about } \\
\text { AIDS and sexual health }\end{array}$} & \multicolumn{3}{|c|}{$\begin{array}{l}\text { Hope to get knowledge of AIDS and sexual } \\
\text { disease from parents, teachers or experts }\end{array}$} \\
\hline & Male students & Female students & Total & Male students & Female students & Total \\
\hline \multicolumn{7}{|l|}{ Grade } \\
\hline Junior class & $394(80.2)$ & 417 (87.7) & $811(83.9)$ & $89(18.1)$ & $130(27.3)$ & $219(22.7)$ \\
\hline Senior class & $358(71.5)$ & $398(83.1)$ & $756(77.1)$ & $61(12.2)$ & $88(18.3)$ & $149(15.2)$ \\
\hline \multicolumn{7}{|l|}{ Region } \\
\hline Central city & $520(71.7)$ & $664(86.4)$ & $1184(79.3)$ & $119(16.4)$ & $179(23.3)$ & $398(20.0)$ \\
\hline Non-central city & $232(86.8)$ & $151(85.1)$ & $383(84.5)$ & 31 (11.6) & $39(20.9)$ & $70(15.6)$ \\
\hline Total & 75.8 & 85.4 & 80.5 & 15.1 & 22.9 & 18.9 \\
\hline
\end{tabular}

\section{Expected way to gain knowledge of AIDS and sex}

A relatively low proportion (18.9\%) of the students expected to gain knowledge of AIDS and sex from their parents, teachers, or experts, although this proportion was higher (27.3\%) among junior middle school girls. There were no differences between boys and girls in various grades and regions $\left(\chi^{2}=0.0033 ; \chi^{2}=0.4436, \mathrm{P}>0.05\right)$. The proportion of students with this attitude was significantly higher in central cities $(20.0 \%)$ than in non-central cities $(15.6 \%)\left(\chi^{2}=23.8779, \mathrm{P}<0.05\right)$, and in junior students $(22.7 \%)$ compared to senior students $(15.2 \%)\left(\chi^{2}=17.6778, \mathrm{P}<0.05\right)$. Overall, more female students $(22.9 \%)$ than male students $(15.1 \%)$ expected to learn about AIDS and sex from parents, teachers, or experts $\left(\chi^{2}=18.9411\right.$, $\mathrm{P}<0.05$ ) (Table 2).

\section{Assessment of knowledge acquisition about AIDS}

\section{Institution of AIDS health education}

Our research found that $54.5 \%$ of students had received no education about AIDS prevention. This phenomenon did not differ between male and female students in various grades $\left(\chi^{2}=0.0192, \mathrm{P}>0.05\right)$ or regions $\left(\chi^{2}=13.35, \mathrm{P}<0.05\right)$. Non-central cities showed a higher proportion $(88.9 \%)$ than central cities $(44.1 \%)\left(\chi^{2}=282.3064, \mathrm{P}<0.05\right)$, but there were no differences between junior middle school students and senior middle school students in receiving AIDS prevention education $\left(\chi^{2}=2.4847, \mathrm{P}>0.05\right)$. There were also no differences in the AIDS education received by male and female students $\left(\chi^{2}=0.0061, \mathrm{P}>0.05\right)$ (Table 3$)$.

\section{Talking about AIDS with families}

Overall, $76.3 \%$ of students had not talked with families, friends, or classmates about AIDS. There were no differences between male students and female students in various grades $\left(\chi^{2}=0.0010, \mathrm{P}>0.05\right)$, although there was a significant difference in different regions $\left(\chi^{2}=\right.$ $9.6398, \mathrm{P}<0.05)$. A higher proportion of students from non-central cities had not talked about AIDS (84.9\%) compared to students from central cities $(73.7 \%)\left(\chi^{2}=24.5875, \mathrm{P}<0.05\right)$. This proportion was also significantly higher in junior middle school students $(75.5 \%)$ than in senior middle school students $(66.9 \%)\left(\chi^{2}=17.2309, \mathrm{P}<0.05\right)$, and in male students $(73.8 \%)$ compared to female students $(68.4 \%)\left(\chi^{2}=6.7596, \mathrm{P}<0.05\right)$ (Table 3$)$. 


\section{Knowledge about AIDS transmission}

Our results revealed that $38.3 \%$ of students reported false-transmission methods of AIDS and incomplete answers. There were no differences in the proportion of false answers reported between boys and girls in different regions and grades $\left(\chi^{2}=0.0833 ; 1.3999, \mathrm{P}>\right.$ $0.05)$, and this proportion was significantly higher in students from non-central cities $(57.8 \%)$ than in those from central cities $(32.4 \%)\left(\chi^{2}=95.4928, \mathrm{P}<0.05\right)$. Significantly more junior middle school students provided false or incomplete answers $(51.7 \%)$ compared to senior middle school students $(25.1 \%)\left(\chi^{2}=145.1038, \mathrm{P}<0.05\right)$. There was no difference between the proportion of boys and girls who provided false answers about how AIDS is transmitted $\left(\chi^{2}=0.0052, \mathrm{P}>0.05\right)($ Table 3$)$.

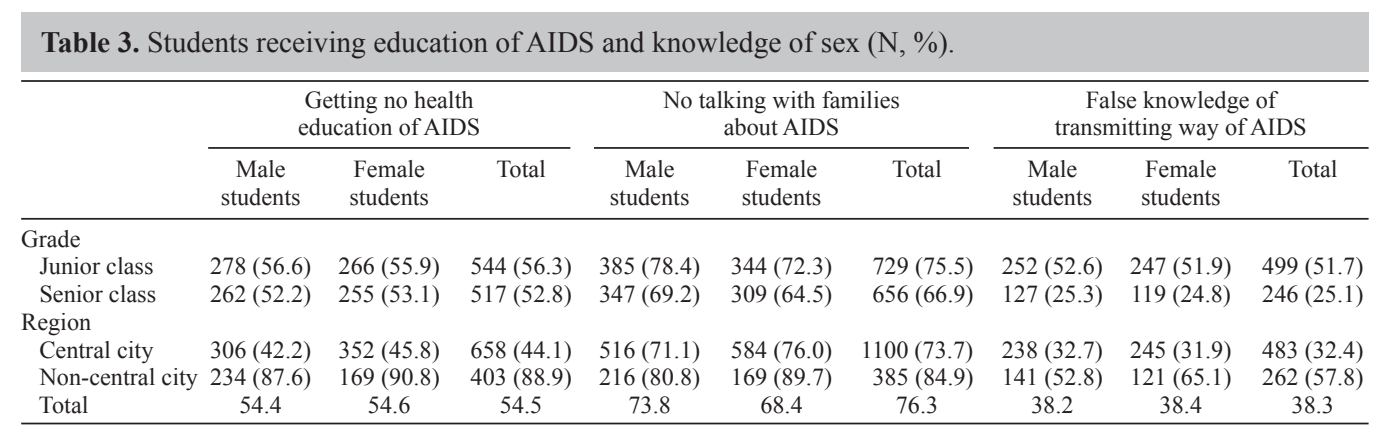

\section{Contact with AIDS in daily life}

Common contact with AIDS in daily life included handshake, sharing cups, toilets, and school things, and studying in the same classes, etc., for which $28.8 \%$ of students gave false answers. There was no difference in the false-answer rate between boys and girls in different grades $\left(\chi^{2}=5.3049, \mathrm{P}<0.05\right)$ or different regions $\left(\chi^{2}=1.2105, \mathrm{P}>0.05\right)$. The proportion of false answers was significantly higher in respondents from non-central cities $(47.6 \%)$ compared to central cities $(23.1 \%)\left(\chi^{2}=102.2414, \mathrm{P}<0.05\right)$ and in junior middle school students $(33.9 \%)$ compared to senior middle school students $(23.8 \%)\left(\chi^{2}=24.5536\right.$, $\mathrm{P}<0.05)$; however, there was no difference between boys and girls $\left(\chi^{2}=0.1621, \mathrm{P}>0.05\right)$ (Table 4).

\section{Willingness to study with patients with AIDS in the same class}

Overall, $91.2 \%$ of students were reluctant to study with patients with HIV/AIDS in the same class. There was no difference between boys and girls in different grades $\left(\chi^{2}=0.0018\right.$, $\mathrm{P}>0.05)$, but there was a significant difference in different regions $\left(\chi^{2}=13.2235, \mathrm{P}<0.05\right)$. Junior middle school students were significantly less willing $(93.5 \%)$ to have a classmate with AIDS than were senior middle school students $(88.9 \%)\left(\chi^{2}=12.7729, \mathrm{P}<0.05\right)$, and the proportion of unwilling female students was significantly higher $(93.6 \%)$ than that of male students $(88.7 \%)\left(\chi^{2}=13.8722, \mathrm{P}<0.05\right)$; however, no difference was found between respondents from central cities and non-central cities $\left(\chi^{2}=0.0058, \mathrm{P}>0.05\right)$ (Table 4). 
Table 4. Proportion of students' false answer and attitude to knowledge of AIDS (N, \%).

\begin{tabular}{lccccccc}
\hline & \multicolumn{3}{c}{ False knowledge of daily touch } & & \multicolumn{3}{c}{ Reluctance to study with patients with AIDS in the same class } \\
\cline { 2 - 3 } & Male students & Female students & Total & & Male students & Female students & Total \\
\hline Grade & & & & & & & \\
$\quad$ Junior class & $183(37.2)$ & $145(30.4)$ & $328(33.9)$ & $448(91.2)$ & $455(95.6)$ & $903(93.5)$ \\
$\quad$ Senior class & $107(21.3)$ & $126(26.2)$ & $233(23.8)$ & $433(86.4)$ & $438(91.3)$ & $871(88.9)$ \\
Region & & & & & & \\
$\quad$ Central city & $172(23.7)$ & $173(22.5)$ & $345(23.1)$ & $643(88.6)$ & $717(93.3)$ & $1360(91.0)$ \\
Non-central city & $118(44.2)$ & $98(52.6)$ & $216(47.6)$ & $238(89.1)$ & $176(94.6)$ & $414(91.4)$ \\
Total & 29.2 & 28.4 & 28.8 & 88.7 & 93.6 & 91.2 \\
\hline
\end{tabular}

\section{Source, attitude, behavior, and knowledge of sexual behavior}

\section{Source of knowledge about sexual behavior}

Overall, $21.7 \%$ of students had read books, watched videos, and consulted other products about sex. There was no difference between male students and female students in different grades and regions $\left(\chi^{2}=3.1462 ; 0.5818, \mathrm{P}>0.05\right)$. The proportion of students obtaining information about sex from media sources was significantly higher $(23.2 \%)$ than that of students from non-central cities $(17.6 \%)\left(\chi^{2}=6.3188, \mathrm{P}<0.05\right)$, and that of junior middle school students was significantly lower $(12.7 \%)$ than that of senior middle school students $(30.5 \%)$ $\left(\chi^{2}=90.4808, \mathrm{P}<0.05\right)$. The proportion of boys consulting books, videos, and other media about sex was significantly higher $(28.6 \%)$ than that of girls $(14.5 \%)\left(\chi^{2}=145.5517, \mathrm{P}<0.05\right)$ (Table 5).

\begin{tabular}{|c|c|c|c|c|c|c|c|c|c|}
\hline & \multicolumn{3}{|c|}{$\begin{array}{l}\text { Source of sexual knowledge } \\
\text { from books and videos }\end{array}$} & \multicolumn{3}{|c|}{$\begin{array}{c}\text { Approval to sexual behavior } \\
\text { before marrige }\end{array}$} & \multicolumn{3}{|c|}{$\begin{array}{c}\text { Experience of sexual } \\
\text { intercourse }\end{array}$} \\
\hline & $\begin{array}{c}\text { Male } \\
\text { students }\end{array}$ & $\begin{array}{l}\text { Female } \\
\text { students }\end{array}$ & Total & $\begin{array}{l}\text { Male } \\
\text { students }\end{array}$ & $\begin{array}{l}\text { Female } \\
\text { students }\end{array}$ & Total & $\begin{array}{c}\text { Male } \\
\text { students }\end{array}$ & $\begin{array}{l}\text { Female } \\
\text { students }\end{array}$ & Total \\
\hline \multicolumn{10}{|l|}{ Grade } \\
\hline Junior class & $75(15.2)$ & $48(10.1)$ & $123(12.7)$ & $44(8.9)$ & $20(4.2)$ & $64(6.6)$ & $3(0.6)$ & $1(0.2)$ & $4(0.4)$ \\
\hline Senior class & 209 (41.7) & $90(18.6)$ & $299(30.5)$ & $126(25.1)$ & $71(14.8)$ & $197(20.1)$ & $15(2.9)$ & $3(0.6)$ & $18(1.8)$ \\
\hline \multicolumn{10}{|l|}{ Region } \\
\hline Central city & $226(31.2)$ & $121(15.8)$ & $347(23.2)$ & $141(19.4)$ & 84 (10.9) & $225(15.1)$ & 14 (1.9) & $3(0.4)$ & $17(1.1)$ \\
\hline Non-central city & $58(21.7)$ & $22(9.1)$ & $80(17.6)$ & $29(10.8)$ & $7(3.8)$ & $36(7.9)$ & $4(1.5)$ & $1(0.5)$ & $5(1.1)$ \\
\hline Total & 28.6 & 14.5 & 21.7 & 17.1 & 9.5 & 13.4 & 1.8 & 0.4 & 1.1 \\
\hline
\end{tabular}

\section{Attitude about sexual behavior}

Overall, 13.4\% of students approved of engaging in sexual intercourse before marriage. There was no difference in approval between boys and girls in different grades $\left(\chi^{2}=\right.$ $0.4863, \mathrm{P}>0.05)$, but there was a significant difference between male students and female students in different regions $\left(\chi^{2}=4.3565, \mathrm{P}<0.05\right)$. Students from central cities showed a significantly higher approval rate $(15.1 \%)$ compared to those in non-central cities $(7.9 \%)\left(\chi^{2}=\right.$ $15.1775, \mathrm{P}<0.05)$, and junior middle school students had a significantly lower approval rate $(6.6 \%)$ than did senior middle school students $(20.1 \%)\left(\chi^{2}=76.0422, \mathrm{P}<0.05\right)$. The propor- 
tion of male students approving of sex before marriage was significantly higher $(17.1 \%)$ than that of female students $(9.5 \%)\left(\chi^{2}=24.1643, \mathrm{P}<0.05\right)$ (Table 5).

\section{Sexual intercourse experience}

Overall, 0.4 and $1.8 \%$ of junior and senior middle school students reported having had sexual intercourse, respectively. There was no difference between male students and female students from different grades and regions $(\mathrm{P}>0.05)$. The proportion of sexually active junior middle school students was significantly lower $(0.2 \%)$ than that of senior middle school students $(0.6 \%)\left(\chi^{2}=8.8043, \mathrm{P}<0.05\right)$. Among male students, there was no difference between central cities and non-central cities $\left(\chi^{2}=0.0038, \mathrm{P}>0.05\right)$ (Table 5).

\section{DISCUSSION}

AIDS is currently developing rapidly in China (Huang et al., 2011). The most effective method of reducing the spread of the disease is to popularize basic knowledge about AIDS prevention to youth and to the general population, and to help them establish healthy behaviors (Trani et al., 2006). However, in China, most young people have poor and false knowledge about sex and reproduction, and are consequently confused, nervous, fearful, and even unreasonably distressed, which is mainly due to their poor knowledge of reproduction or weak efficacy (Hong et al., 2011b). Therefore, it is very important to investigate the attitudes and behaviors in relation to AIDS in middle school students.

\section{Need for knowledge}

Our results found that $80.5 \%$ of students thought it very necessary to obtain an education related to AIDS and sexual knowledge, $83.9 \%$ of whom were junior middle school students, $77.1 \%$ were senior middle school students, $79.3 \%$ were students in central cities, and $83.9 \%$ were students in non-central cities. This result demonstrated that middle school students are paying attention to knowledge of AIDS and sexual health education, and that development of such education is urgently needed (Yang et al., 2010), especially in non-central cities with poor education levels (Lau et al., 2009). Our study also found that fewer students expected to receive knowledge of AIDS and sex from their parents, teachers, or experts (18.9\%). Overall, $76.3 \%$ of students had not talked about HIV/AIDS with their families, which suggested that home education is not an effective means by which students can gain such knowledge, which is likely due to the boredom education model for adults, and easily arouses students' opposed emotions. Therefore, new methods of sex and AIDS education should be developed that will be favorable to students, such as some attractive and interesting games about sex and reproductive health, to improve and ensure the efficacy (Swain et al., 2011).

\section{Mastering of basic knowledge about AIDS}

The present investigation showed that $54.5 \%$ of students did not receive any formal education of AIDS in Luoyang city. By contrast, a 1999 report from an American disease control center showed that $90.6 \%$ of American students had received formal education about AIDS 
(Urada et al., 2012). This result suggested that it is very necessary to develop HIV/AIDS education programs for middle school students as soon as possible (Sirotin et al., 2010). Our results showed that junior middle school students had significantly less knowledge about the risk factors, attitudes, and behaviors about AIDS compared to senior middle school students, as did students from central cities compared with those from non-central cities. In China, we conduct routine education of nine years; therefore, some junior middle school students will enter society after graduation, which means that without access to such education during this phase, this group of students will be illiterate with respect to AIDS. The instruction of education organization states that: "education plans should include at least two special reports or special movements during the junior middle school period" (Shepherd et al., 2010). Education of healthy sexual behavior and AIDS prevention should be integrated in the routine plan of the education department, and be developed widely to reach remote regions (Wang et al., 2010). In addition, the present research exposed that $91.2 \%$ of students were reluctant to study with AIDS/HIV patients in the same class, which suggested that middle school students had incomplete knowledge about AIDS. AIDS prevention is still a large challenge, which requires the cooperation of schools, families, and society, and various styles are needed to effectively convey detailed knowledge to meet the needs of students' emotional and physical health (Ye et al., 2012).

\section{Source of knowledge, attitude, and behavior about sex}

Our findings showed that media, such as books, videos, and CDs, were a main source of sex knowledge, which was more apparent in male senior middle school students; $21.7 \%$ of students had read books or watched videos about sex, $13.4 \%$ of students approved of sexual intercourse before marriage, and $1.1 \%$ of students had engaged in sexual intercourse. Healthy sexual growth and responsible sexual behaviors are necessary bases once adolescents enter adulthood (Rotheram-Borus et al., 2011). The relative risk factors about sexual behavior have a direct impact on adolescents' health. Therefore, the development of appropriate sex and reproductive education is urgently needed for middle school students. Educators and health workers in China should aim to overcome the limitations of the national feudal culture and deal with sexual issues correctly to help adolescents get through the puzzling period peacefully, especially during the earlier and middle phase when individuals are going through great changes in their bodies and emotions (Mishra et al., 2012). The introduction of knowledge about contraception and disease prevention during the junior and senior middle school phase of life will be beneficial for reducing the transmission of HIV/AIDS and aversion toward condoms.

\section{REFERENCES}

Hong Y, Fang X, Zhou Y, Zhao R, et al. (2011a). Factors associated with sexually transmitted infection underreporting among female sex workers in China. J. Women Health 20: 129-136.

Hong Y, Poon AN and Zhang C (2011b). HIV/STI prevention interventions targeting FSWs in China: a systematic literature review. AIDS Care 23 (Suppl 1): 54-65.

Huang ZJ, Wang W, Martin MC, Nehl EJ, et al. (2011). "Bridge population": sex workers or their clients?-STI prevalence and risk behaviors of clients of female sex workers in China. AIDS Care 23 (Suppl 1): 45-53.

Jain AK, Saggurti N, Mahapatra B, Sebastian MP, et al. (2011). Relationship between reported prior condom use and current self-perceived risk of acquiring HIV among mobile female sex workers in southern India. BMC Public Health 11 (Suppl 6): S5. 
Khan MS, Unemo M, Zaman S and Lundborg CS (2011). HIV, STI prevalence and risk behaviours among women selling sex in Lahore, Pakistan. BMC Infect. Dis. 11: 119.

Lau JT, Wan SP, Yu XN, Cheng F, et al. (2009). Changes in condom use behaviours among clients of female sex workers in China. Sex Transm. Infect. 85: 376-382.

Lauszus FF, Nielsen JL, Boelskifte J and Falk J (2012). Sexual practice associated with knowledge in adolescents in ninth grade. Dan. Med. J. 59: A4474.

Liao M, Bi Z, Liu X, Kang D, et al. (2012). Condom use, intervention service utilization and HIV knowledge among female sex workers in China: results of three consecutive cross-sectional surveys in Shandong Province with historically low HIV prevalence. Int. J. STD AIDS 23: e23-e29.

Mishra S, Ramanaik S, Blanchard JF, Halli S, et al. (2012). Characterizing sexual histories of women before formal sexwork in south India from a cross-sectional survey: implications for HIV/STI prevention. BMC Public Health 12: 829.

Rotheram-Borus MJ, Wu Z, Liang LJ, Li L, et al. (2011). Reductions in sexually transmitted infections associated with popular opinion leaders in China in a randomised controlled trial. Sex Transm. Infect. 87: 337-343.

Shepherd J, Kavanagh J, Picot J, Cooper K, et al. (2010). The effectiveness and cost-effectiveness of behavioural interventions for the prevention of sexually transmitted infections in young people aged 13-19: a systematic review and economic evaluation. Health Technol. Assess. 14: 1-iv.

Sirotin N, Strathdee SA, Lozada R, Abramovitz D, et al. (2010). Effects of government registration on unprotected sex amongst female sex workers in Tijuana; Mexico. Int. J. Drug Policy 21: 466-470.

Swain SN, Saggurti N, Battala M, Verma RK, et al. (2011). Experience of violence and adverse reproductive health outcomes, HIV risks among mobile female sex workers in India. BMC Public Health 11: 357.

Trani F, Altomare C, Nobile CG and Angelillo IF (2006). Female sex street workers and sexually transmitted infections: their knowledge and behaviour in Italy. J. Infect. 52: 269-275.

Urada LA, Malow RM, Santos NC and Morisky DE (2012). Age differences among female sex workers in the Philippines: sexual risk negotiations and perceived manager advice. AIDS Res. Treat. 2012: 812635.

Wang B, Li X, Stanton B, Zhang L, et al. (2010). Alcohol use, unprotected sex, and sexually transmitted infections among female sex workers in China. Sex Transm. Dis. 37: 629-636.

Wu S, Tian L and Xu F (2011). Induced abortion and relevant factors among women seeking abortion in Nanjing, China. Gynecol. Obstet. Invest. 71: 87-92.

Yang C, Latkin C, Luan R and Nelson K (2010). Peer norms and consistent condom use with female sex workers among male clients in Sichuan Province, China. Soc. Sci. Med. 71: 832-839.

Ye X, Shang M, Shen T, Pei B, et al. (2012). Social, psychological, and environmental-structural factors determine consistent condom use among rural-to-urban migrant female sex workers in Shanghai, China. BMC Public Health 12: 599 .

Zhou H, Wang XY, Ye F, Gu HH, et al. (2012). Contraceptive knowledge, attitudes and behavior about sexuality among college students in Beijing, China. Chin. Med. J. 125: 1153-1157.

Zhu BY, Bu J, Huang PY, Zhou ZG, et al. (2012). Epidemiology of sexually transmitted infections, HIV, and related high-risk behaviors among female sex workers in Guangxi Autonomous Region, China. Jpn. J. Infect. Dis. 65: 75-78. 